\title{
Prediction of Compressive Strength and Modulus of Rupture of Mortar Containing Added Ash Bagasse
}

\author{
H. L. Chavez García ${ }^{1}$, W. Martinez Molina ${ }^{1}$, E. M. Alonso Guzman ${ }^{1}$, A. A. Torres Acosta ${ }^{2}$, J. T. Perez Quiroz ${ }^{2}$, \\ J. A. Bedolla Arroyo ${ }^{3}$, C. Lara Gómez ${ }^{1}$ and F. M. Gonzalez Valdez ${ }^{1}$ \\ ${ }^{1}$ School of Civil Engineering, University Michoacana de San Nicolas de Hidalgo, Morelia, Michoacan, Mexico, 58040 \\ ${ }^{2}$ Mexican Institute of Transport, Ministry of Communications and Transport, Sanfandila, Queretaro, Mexico, 76703 \\ ${ }^{3}$ Faculty of Architecture, University Michoacana de San Nicolas de Hidalgo, Morelia, Michoacan, Mexico, 58040
}

\begin{abstract}
This paper focuses on the mechanical and physical evaluation of Portland cement mortars, CPC, with the addition of ash sugarcane bagasse (CBC) and a high-range water-reducing and super-plasticizing admixture (SikaViscoCrete PC ${ }^{\circledR}$ 2500), and its effect is discussed mainly in terms of the mechanical strength properties through destructive and non-destructive testing. Each of the additions is made in three different percentages and specimens each of the three percentages were submitted to destructive (ultrasonic pulse velocity, resistivity) and non-destructive testing (compressive strength and modulus of rupture). From the results of the destructive and non-destructive testing, correlations were obtained using multiple linear regression. This indicated the best model according to the correlation factor obtained.
\end{abstract}

\section{Keywords-compressive strenght; mostar; ash bagasse}

\section{INTRODUCTION}

The cement industry has for a long time been intervening in climate change. Cement is an essential component in the economies of many developing countries, as an element needed for the construction of buildings and roads. Eighty percent of the cement produced today is used in developing countries. But the production of cement involves the emission of a lot of $\mathrm{CO} 2$ into the atmosphere, and cement produces $5 \%$ of the total global emissions of carbon dioxide, the main cause of global warming [1].

However, everything can change, and several companies have developed a new generation of cements that do not harm the environment, allowing an almost complete reduction of direct emissions of $\mathrm{CO} 2$ into the atmosphere. To achieve this, limestone has been replaced as the raw material by solid waste from thermal power plants $[2,1]$.

With this new production technique a triple objective has been achieved: carrying out efficient management of waste through recycling, contributing to the preservation of the natural resources of the planet and avoiding the direct emission of greenhouse gases into the atmosphere, by reducing the calcination of the raw material. At the same time, the developed technology can reduce by about half the energy demand of the cement synthesis process [3].

Thus, the new generation of ecological cements represents a revolution in the current model of production which will significantly contribute to mitigating the adverse effects on the environment arising from the activity of the cement industry [4].
The use of additives to improve the properties of concrete has been practised since the last century. These include superthinners, retarders and accelerators, waterproofing, etc. In the early sixties there began to be massive use of plasticizers, products that today are the most widely used worldwide, due to their ability to reduce the mixing water required and thereby achieve concrete that is more durable and economical.

On the other hand, non-destructive testing has come into use. Non-destructive testing may be performed to measure the characteristics of a test object such as its size, shape, configuration, structure, including alloy content, hardness, grain size, etc. $[5,6]$. Non-destructive testing is based on the measurement of material properties, and in the case of ultrasonic methods it seeks to establish relationships between the various parameters of the propagation constants and the existence of defects in a material. The properties measured differ in nature, and range from echogenicity (the ability to produce echoes) for imaging to the determination of elastic constants, sometimes by studying a spread of complex modes $[7,8,6]$.

The importance of the work was based on developing a series of destructive and non-destructive mortar tests, but using additive and mineral admixtures in the mixtures. These materials were selected so as to allow us to significantly improve the physical and mechanical stresses to which the material was submitted by developing cubic, cylindrical (bucket) and prismatic samples. Also included were experiments on a high-range water-reducing and super-high performance plasticizing concrete admixture including controlled air (SikaViscoCrete PC 2500). Finally, with the test results a multiple linear regression technique was used to generate prediction models of the compressive strength and modulus of rupture of the mortar.

\section{TESTING}

The characterization of the $\mathrm{CBC}$ obtained from the sugar mill located in the city of Lazaro Cardenas, Michoacan, Mexico was conducted. According to ASTM C618 03,the ash cane bagasse used is classified as Class $\mathrm{F}$ : produced by calcining anthracite or bituminous coal. These ashes possess pozzolanic properties.

The additive used is a high-range water-reducing superhigh performance third generation air controlled plasticizing concrete admixture. It does not contain chloride, and meets the ASTM C standard ASTM C 494 Type F 10127 Type I. The 
significant reduction of water helps give it high fluidity and concrete results with very high performance. The SikaViscoCrete PC 2500 was added to the mixing water for the mixture. The percentages used were $0.5 \%, 1.0 \%$ and $1.5 \%$ relative to the cement weight ( 4.5 to $14.0 \mathrm{ml} / \mathrm{kg}$ of cement).

The cement used is a Toltec RS CPC 30R. This is a Compound Portland Cement, Class 30, with resistance specified to 3 days $20 \mathrm{MPa}$ and sulphate-resistant (4140NNCCE NMX-C-2004). The selection of this cement availability acquisition is made.

This cement has high resistance to the action of sulphates and is used solely in concrete exposed to severe cases of such action, especially where the soil or ground water has a high sulphate content.

River sand with a high silica content was used, from the HuajúmbaroCuervoriver in the municipality of Zinapécuaro, Michoacan, Mexico. This material was sieved, using only material passing the \# 16 mesh and \# 30 mesh, thus retaining materials with characteristics similar to Ottawa sand, i.e. with high silica content.

Tests were performed on the high quality river sand used in the processing of specimens. The tests performed were: current humidity, moisture absorption and release, dry Volumetric Mass, Volumetric Mass dry and hits, colorimetry, and sedimentation.

Prismatic specimens were made with seven mixtures, the composition of which was as follows: 1 ) with $0.5 \%$ additive offluidizing and $0 \%$ of $\mathrm{CBC}, 2$ ) with $1 \%$ of plasticizer additive and $0 \% \mathrm{CBC}, 3)$ with $1.5 \%$ offluidizing additive and $0 \%$ of CBC, 4)with $0 \%$ PC 2500 and 3\% CBC, 5) with $0 \%$ PC 2500 and $5 \% \mathrm{CBC}, 6)$ with $0 \%$ PC 2500 and $7 \% \mathrm{CBC}$, and finally 7)a mixture without additives as the control.

The test ages were 7, 14, 28, 45, 90 and 150 days. Once the mixtures had developed, specimens were cast and proceeded to the appropriate testing ages programmed, in the proportions indicated in Table 1 and Table 2 with the additive used.

To prepare the mortar cubes from the different additions, stainless steel and bronze moulds that meet the dimensions specified by the relevant standard (ASTM C 109M, 2002) were used. First, it is necessary to coat the mould with a release agent, the purpose of which is after 24 hrs remove from the mold without a problem, as shown in Figure 1.

TABLE I. PROPORTIONS OF MIXTURE

\begin{tabular}{|c|c|}
\hline Aggregate & Amount \\
\hline Cement & $1908 \mathrm{~g}$ \\
\hline Sand & $5247 \mathrm{~g}$ \\
\hline Water & $1927 \mathrm{ml}$ \\
\hline Water/Cement ratio (w/c) & 1.01 \\
\hline Fluidity & $115 \mathrm{~cm}$ \\
\hline
\end{tabular}

The fillings of the moulds are made of four layers of approximately equal thickness (ASTM C 109M I., 2002) in each layer of mortar, and before the subsequent filling, they were tamped with 8 small bumps on the surface, the blows being delivered in different directions for each layer. As shown in Figure 2, the ram with the punches has a rectangular shape at its base, approximately $2.5 \mathrm{~cm} \times 1.25 \mathrm{~cm}$.

TABLE II. PROPORTIONINGOF SIKAVISCOCRETE®PC2500ACCORDING TO THE PERCENTAGEUSED

\begin{tabular}{|c|c|c|c|c|}
\hline $\begin{array}{c}\text { Additive } \\
\text { Percent }\end{array}$ & $\begin{array}{c}\text { Water } \\
\text { amount } \\
\text { (ml) }\end{array}$ & $\begin{array}{c}\text { Cement } \\
\text { amount } \\
\text { (g) }\end{array}$ & $\begin{array}{c}\text { Additive } \\
\text { Percent }\end{array}$ & $\begin{array}{c}\text { Water } \\
\text { amount (ml) }\end{array}$ \\
\hline $0.5 \%$ & 1440 & 1908 & 5248 & 108 \\
\hline $1 \%$ & 1256 & 1908 & 5248 & 106 \\
\hline $1.5 \%$ & 1341.50 & 2309 & 6350 & 106 \\
\hline
\end{tabular}

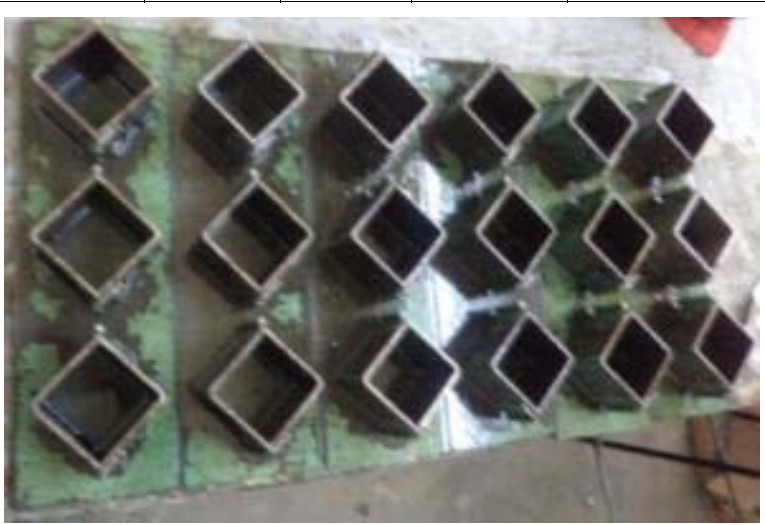

FIGURE I. MOULD CUBES WITH RELEASE AGENT
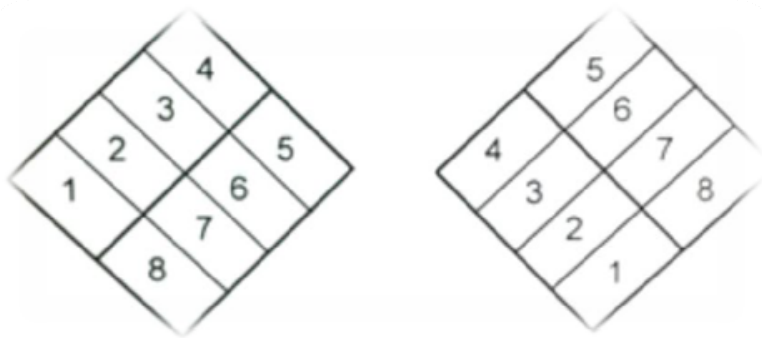

FIGURE II. EXAMPLE OF APPLYING BLOWS TO THE FILLING OF THE MOULDS FOR CUBES

\section{RESULTS}

\section{A. Ultrasonic Pulse Velocity}

The equipment used for this test was a dual ultrasonic and rebound testing machine with automatic introduction of the results of sclerometer model 58-e0049/B (CONTROLS), velocity meter ultrasonic pulses; with a frequency range of 24 to $150 \mathrm{kHz}$; receiver input impedance $1 \mathrm{M}$; RS 232 output. with the ability to connect to an oscilloscope; measuring a propagation time of 0.1 to $1999.9 \mu \mathrm{s}$; speed pulses ranging from 1 to 10 per second; $1 \mu$ s accuracy; transmitter output up to $1500 \mathrm{~V}$. It works with internal rechargeable batteries and includes a sclerometer specifically for testing with an impact energy of 2.207NM.

The equipment has two transducers, a transmitter and a receiver, which must have a good contact with the surface to be tested, and for this purpose a conductive medium or gel is used. 
This gel is provided by the computer manufacturer; however, measurements were made using both a hand sanitizer and the one provided by the manufacturer, and the readings were found to have minimal differences, which is why it was decided to use the antibacterial gel for making the required pulse rate measurements. The use of another gel was necessary because the manufacturer provided an insufficient amount for the planned measurements, and the acquisition times required prolonged gel application.

Importantly, when performing these tests, the samples were kept covered with a damp cloth in order to avoid variations in the humidity of the samples and thus obtain reproducible results.

From Figure 3, one can see that the mixtures with fluidizing admixture in three percentages presented high-range results for all the ages tested. In the case of $\mathrm{CBC}$, the results were lower than the control values, but for later ages the trend is the same.

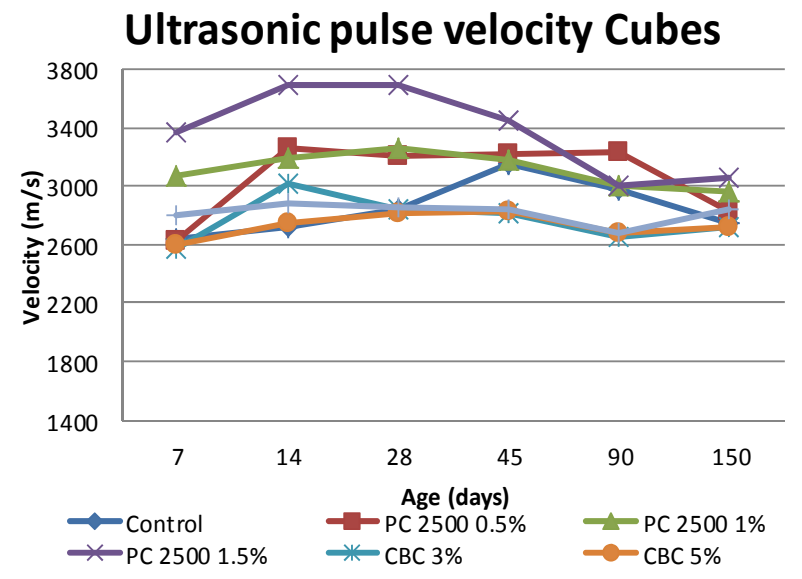

FIGURE III. COMPARISON OF THE PULSE RATES OBTAINED IN CUBIC SPECIMENS

Figure 4 shows that, just as in the cubic specimens, the beams made with the fluidizing additive presented higher readings than those with the $\mathrm{CBC}$, and that the $\mathrm{CBC}$ mixtures vary in time.

In testing the ultrasonic pulse velocity, the wave travels through the solid or liquid found in the pores of the sample. At the earliest ages, the porosity is higher in all samples and there is both water and solid media for this travelling wave. At later ages, this porosity is reduced by the reaction of the cement, but reaches a limit beyond which this porosity is very little reduced. In Figure 4 we can see that the pulse of the samples that contain a percentage of $1.5 \%$ of fluidizing additive is the fastest, indicating that their porosity is less.

\section{B. Electrical Resistivity}

The measurements for this test are performed with a resist meter equipment (Nilsson) that measures electrical resistivity in soils and porous materials. This test was conducted only on cubes and beams.

For the electrical resistivity test, the results are presented in Figure 5, from which one can observe that the highest values were the fluidizing admixtures with percentages of $1.5 \%$ and $0.5 \%$, where the values were below those seen for the ages of 7 , 14 and 28 days and above those for the ensuing ages, while in the case of the $1 \%$ admixture the values were more variable. The $\mathrm{CBC}$ values were lower in all age groups compared to the controls. This behavior was repeated in the case of the beams.

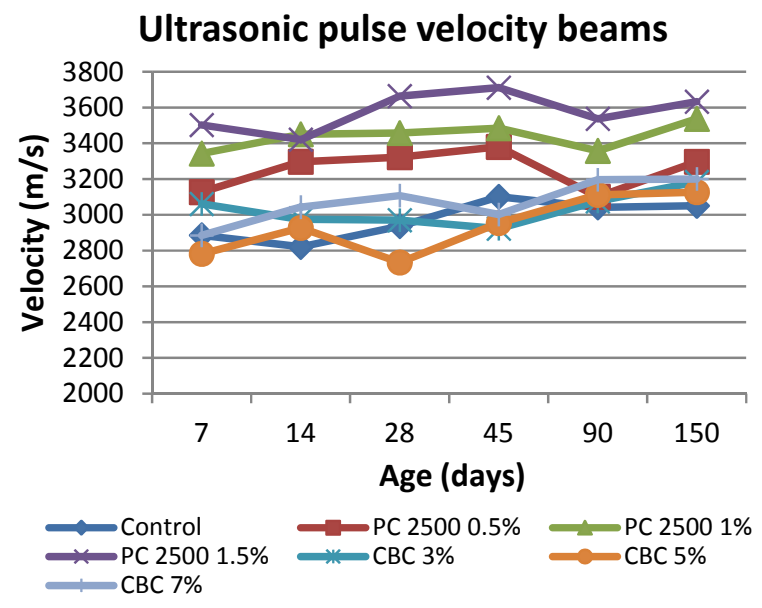

FIGURE IV. PULSE SPEEDS OBTAINED IN BEAMS

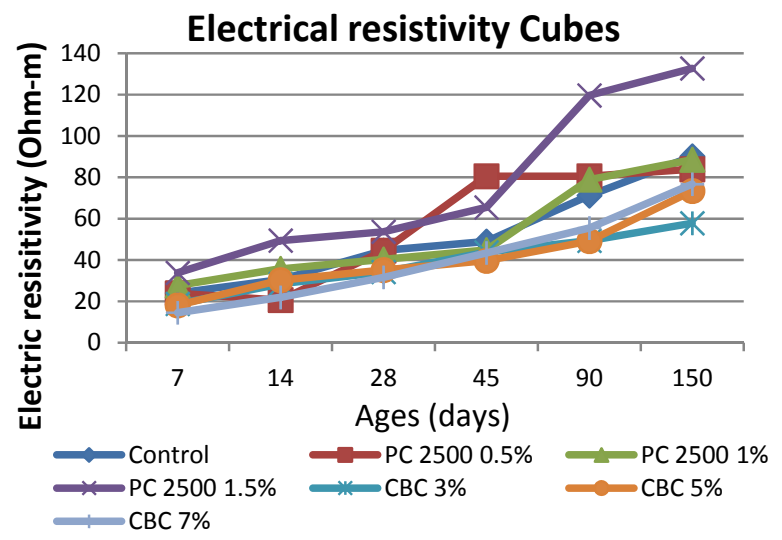

FIGURE V. ELECTRICAL RESISTIVITY READINGS OBTAINED FOR CUBIC SAMPLES

From comparison of the pulse rate and electrical resistivity results, the samples with $1.5 \%$ fluidizing additive have higher resistivity, and it is shown that this represents lower porosity. This also results in the destructive tests listed below.

\section{Resistance to Simple Compression}

These results are presented in Figure 6, where the specimens that showed the highest compressive strength were the fluidizing admixtures in the three percentages, followed by the $\mathrm{CBC}$ and the lowest strength specimens were the controls. This trend is repeated in the prismatic test specimens for flexural strength. 


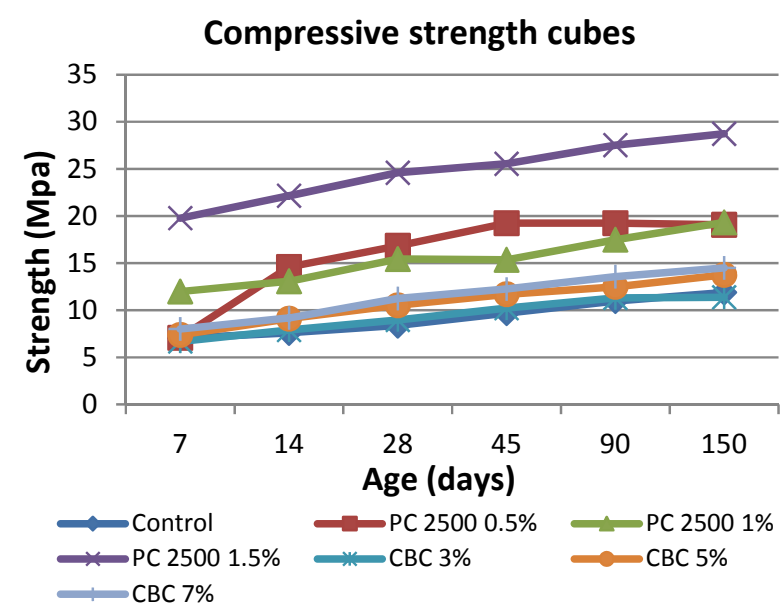

FIGURE VI. COMPARISON OF COMPRESSIVE STRENGTH BETWEEN THE VARIOUS MIXTURES

\section{Bending}

The specimens that showed the most resistance to bending were those with all three percentages of fluidizing additive, followed by $\mathrm{CBC}$ and finally the lowest strength specimens were the controls.

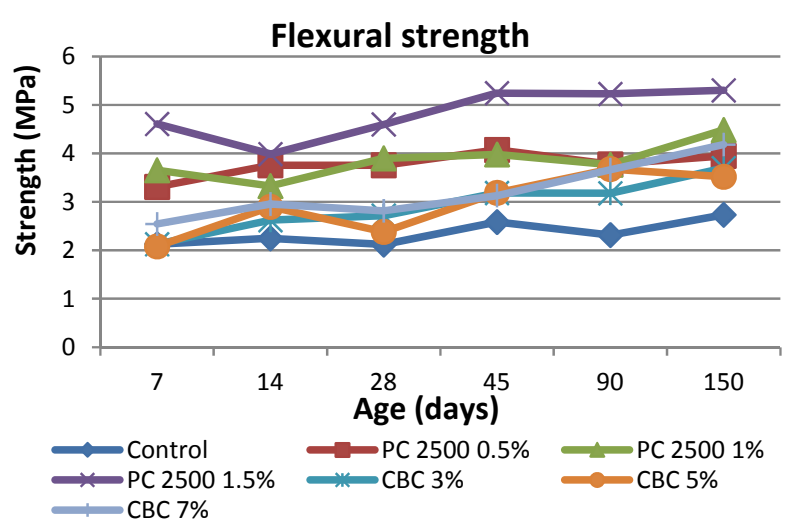

FIGURE VII. FLEXURAL STRENGTHS OBTAINED IN PROCESSED BEAMS

Upon completion of the destructive and non-destructive testing, we worked with the results to generate predictive models ofboth the compressive strength and the modulus of rupture. The two best models obtained, Equations 1 and 2, according to the correlation factors, are presented below.

Predictive model of resistance to simple compression:

$\mathrm{C}=-119.9931+(0.00086 *$ age $)+(58.2779 * \%$ additive $)+$ $(4.7378 * \%$ of $\mathrm{CBC})+(1.1228 * \mathrm{D})+(0.0571 * \mathrm{vpu})$.

$$
\mathrm{R}=0.9618
$$

where:

$\mathrm{C}=$ compressive strength $(\mathrm{MPa})$

Mortar age $=$ age (days)
$\%=$ Percentage of SikaViscoCrete PC 2500 additive employed

$\mathrm{CBC} \%=$ percentage of bagasse ash

$\mathrm{re}=$ electrical resistivity $(\mathrm{ohm}-\mathrm{m})$

$\mathrm{vpu}=$ ultrasonic pulse velocity $(\mathrm{m} / \mathrm{s})$

$\mathrm{R}=$ correlation factor.

Predictive model of modulus of rupture:

$\mathrm{MR}=-32.2873+(0.0156 *$ age $)+(5.1741 * \%$ additive $)+$ $(0.7659 * \% \mathrm{CBC})+(0.0258 * \mathrm{re})+(0.0183 * \mathrm{vpu})$.

with $\mathrm{R}=0.9101$

where:

$\mathrm{MR}=$ modulus of rupture $(\mathrm{MPa})$

Mortar age $=$ age (days)

$\%=$ percentage of SikaViscoCrete PC 2500 additive employed

$\mathrm{CBC} \%=$ percentage of bagasse ash
$\mathrm{re}=$ electrical resistivity $(\mathrm{ohm}-\mathrm{m})$
$\mathrm{vpu}=$ ultrasonic pulse velocity $(\mathrm{m} / \mathrm{s})$
$\mathrm{R}=$ correlation factor.

\section{CONCLUSIONS}

The materials used as an additive in this investigation have significant effects on the physical-mechanical behaviour of mortars. These are mainly mechanical, as they improve the resistance to compression and bending, emphasizing compression according to the results. It can be concluded that the use of an appropriate percentage of additive is feasible in preparing mortars used in construction, due to the improved physical-mechanical properties presented here. The fact of increasing resistance throughthese admixtures contributes to reduced consumption of Portland cement, the production of which can therefore be decreased. The specimens that showed the most favorable results had the addition ofSikaViscoCrete ${ }^{\circledR}$ PC 2500 in three percentages, with the optimum being $1.5 \%$.

The results of the testing of $\mathrm{CBC}$ in non-destructive testing showed unfavorable results in the case of cubic specimens, with values below those of the controls. However, the destructive testing results exceeded the control values, so we conclude that it is feasible to use this as an addition to the mortar to improve its mechanical properties. Adding $\mathrm{CBC}$ to mortar mixes has two major advantages: first, the properties of the mixture and its resistance to compression and bending, second, as the cost of the $\mathrm{CBC}$ is much less than the cement, the cost of the final product will be significantly less, assuming that the $\mathrm{CBC}$ does not require further screening and treatment and does not have to be transported from far away.

The objective of this research, for the conditions raised and in which the work was performed, were achieved, obtaining models for predicting the compressive strength and modulus of rupture. 
Non-destructive tests have a fairly wide field of application, both in engineering and in other areas of knowledge, so it is recommended to conduct further research to document and sustain non-destructive techniques.

\section{ACKNOWLEDGMENT}

The authors thank the Coordination of Scientific Research of the Universidad Michoacana de San Nicolas de Hidalgo and support facilities Materials Laboratory "Ing. Luis Silva Ruelas "of the Faculty of Civil Engineering, and the National Council of Science and Technology (CONACYT) and the SEP program Promep Thematic Network of Mexico.

\section{REFERENCES}

[1] Worrell, E., Price, L., Martin, N., Hendriks, C., and Ozawa, M.L.(2001) Carbon dioxide emissions from the global cement industry.Annual Review of Energy and the Environment, 26, 303-329.

[2] Solomon, S., Plattner, G.-K., Knutti, R., and Friedlingstein, P.(2008) Irreversible climate change due to carbon dioxide emissions.Proceedings of the National Academy of Sciences of the United States of America, 106(6), 1704-1709.

[3] Akash, R.A.O., Kumar Neeraj, J.H.A., Sudhir, M. (2007) Use of recycled aggregates from construction.Resources Conservation and Recycling, 50 (1), 71-81.

[4] Sahmaran, M., Christianto, H.A., and Özgür, I.Y.(2006) The effect of chemical admixtures and mineral additives on the properties of selfcompacting mortars.Cement \& Concrete Composites, 28, 432-440.

[5] Sengul, O. (2013) Factors affecting the electrical resistivity of concrete. Nondestructive Testing of Materials and Structures, RILEM Bookseries 6, pp. 263-269.

[6] Malhotra, V.M., Carino, N.J. (2004)Handbook on nondestructive testing of concrete. Boca Raton: CRC.

[7] Gaete, L., Vargas Hernandez, Y., and Pettorino, A. (2001)Measurement of acoustic parameters in solids II, Spain.

[8] Malhotra, V.M. (1976) Detroit, MI: American Concrete Institute, ACI Monograph N.9. 